the history of crop plants. The author and the publishers (who maintain their usual high standards of production) are to be congratulated on another valuable addition to the literature of tropical agricultural science. Socially and politically, there is no more important science in the world today.

N. W. Simmonds.

\title{
A TALE OF TWO CITIES: THE EFFECTS OF INBREEDING IN HIRO- SHIMA AND NAGASAKI
}

THE EFFECTS OF INBREEDING ON JAPANESE CHILDREN. William J. Schull and James V. Neel. Published by Harper \& Row, New York. E5. 12s. 6d.

This book reports the results of a remarkably detailed and painstaking survey on consanguinity in Hiroshima and Nagasaki, the individuals studied being ascertained by the two authors when they were investigating the genetic effects of the atomic bombs.

Between I 948 and I953 there were 76,626 pregnancies in the two cities and because in Japan the rate of consanguineous marriages is high, in 5346 of these the parents were related. This I948-53 cohort was investigated from 1958-6o and in addition to the lack of bias in ascertainment, the examiners were unaware whether the child they were testing was the product of inbreeding or not, and (most important) adequate data with respect to socio-economic factors were available.

The effects investigated were mortality and morbidity, and after the elimination of all children whose parents had received a significant amount of radiation, the final number of offspring of consanguineous parents was I 789 in Hiroshima and 2686 in Nagasaki. The controls were selected by taking a to per cent. sample based on the terminal registration digit for the pregnancy. From these were eliminated those who happened to be of consanguineous origin and those born to irradiated parents, and since there were still too many, those whose subterminal digit was 3,6 or 9 . The control series then numbered 1970 in Hiroshima and 2847 in Nagasaki.

The high frequency of consanguineous marriage is not surprising since it accords well with the pattern of family life in Japan. Parents choose mates for their children who will fit peaceably into the common household, who are well-known to them and to their prospective partners and who are of the same economic status (this is very important owing to the heavy burden of present-giving in Japan).

The general statistical problem was, simply: "What is the statistical and biological significance, if any, of parental relationship with mortality and morbidity in the child?" The solution is complicated mainly by extraneous variation and by markedly disparate numbers of observations in the various consanguinity classes (principally first cousins, first cousins once removed and second cousins); moreover, corrections have to be made throughout for socio-economic factors. The coefficient of relationship, i.e. the probability of occurrence of an identical gene by descent at a given locus for the two individuals, has been calculated for unrelated individuals and for all the consanguinity classes, and by the application of complicated statistical and computer techniques a series of unspectacular but very interesting results were obtained, some of which follow:

I. There was a small but significant effect of inbreeding on mortality 
in the 9292 pregnancies forming the colort in Hiroshima but none in Nagasaki, and this city difference remains unexplained.

2. In both cities there was a correlation between inbreeding and performance at school-the inbred children did slightly worse. Similarly, with formal mental tests there was a slight but statistically significant depression in the average performance on all tests with increased inbreeding. The authors point out that this would have been appreciably overestimated if adequate allowance for variation in socio-economic status had not been made. Concerning ill-health as measured by absence from school, the inbred children appeared to be as healthy as controls.

3. No consanguinity effect was observed in abnormalities in tooth number and many of these are known to be genetic. One can conclude that the responsible genetic basis is little affected by inbreeding-i.e. it is common, or of a dominant nature, or both.

4. When weight, height and other anthropometric measurements are considered, the means of the measurements are significantly reduced by inbreeding in both cities. Though statistically significant and undoubtedly real, the effect is again modest and there is no evidence to suggest that inbreeding alters the normal pattern of age-dependency of the measurements.

5. When considering the major physical defects the overall data indicate an increase from approximately 8.5 per cent. in the controls to 11.7 per cent. in the children of first cousins. However, in the breakdown there are contradictory findings. In Nagasaki, congenital diseases of the eye and defects of hearing (though particularly in the latter there is much heterogeneity) exhibit the most marked consanguinity effect, and the findings also suggest slighter effects for almost every disease category investigated, and in Nagasaki there is a significant relationship between morbidity and degree of consanguinity. In Hiroshima, on the other hand, although there is a suggestion again of a consanguinity effect in disorders of the eye and ear, yet in many of the other disease categories there is actually less disease in the more inbred, the net result being the absence of an overall consanguinity effect.

6. Although the morbidity rate is lower in Hiroshima than in Nagasaki among the inbred, yet mortality is higher, but the combined impact of mortality and morbidity is remarkably similar in the two cities. It is impossible at the present time either to explain this reciprocal finding or to ascribe it to coincidence. All that can be said is that other investigators testing the effects of inbreeding with Caucasian populations, have tended to report larger effects than those described in the present work. It is not yet clear whether valid racial differences exist or whether the discrepancies stem from differing methodologies.

The most obvious explanation for the present unsensational findings is that the Japanese population has become adjusted to inbreeding, but there still remains the problem of the differences between the two cities. However, this is trivial compared with the contradictory evidence (from other workers) which comes from the study of outcrossing, particularly where hybrid populations are involved. Until we know more, there seems no good reason, on Neel and Schull's evidence, for advising the Japanese to alter their breeding habits. The great point about the survey, however, is the way in which it will serve as an admirable model and yardstick for future investigations, and there are useful suggestions for these. 
The book, which has involved labour which needs to be seen to be believed, will prove a mine of information for methodologists, and mathematicians and statisticians will find much to interest them in the techniques employed. What is required for comparison is a similar survey for an outbreeding population, though it is to be hoped that some substitute for the method of ascertainment used in Hiroshima and Nagasaki will be available for this.

C. A. Glarke.

\section{BOOKS RECEIVED}

GENETICS OF THE NORWAY RAT. Roy Robinson. Pergamon Press, Oxford. 1965. Pp. 804. $E 10$.

SEX-DETERMINATION (4th edition revised). D. A. E. Crewe. Methuen \& Co. Ltd., London, W.C.2. 1965. Pp. 188. 21s.

CHEMICAL MICROBIOLOGY. Anthony H. Rose. Butterworth \& Co. Ltd., London, W.C.2. 1965. Pp. 247. 37s. 6d.

RECHERCHES SUR L'EVOLUTION DES LYGODACTYLES, LEZARDS AFRO-MALCACHES ACTUELS. Georges Pasteur. Travaux de L'Institut Scientifique Cherifien Sere Zoologie, No. 29. Rabat. 1964. Pp. 132.

MODERNE GENETISCHE PROBLEME. S. Karger. Arnold-Bocklin Strasse 25, Basel, Switzerland. 1965. Pp. 144. DM. 22.

GENETICS (2nd edition). Robert C. King. Oxford University Press, London,W.1. 1965. Pp. 450 . 68s.

ELEMENTARY GENETICS (2nd edition). Wilma George. Macmillan, London, W.C.2. 1965. Pp. 198. 21s.

THE PEDIATRIC PATIENT. Sarah R. Gustafson. Pitman Medical Publishing Co. Ltd., 1965. Pp. 216. 50s.

BULETIN DE INFORMARE STINTIFICA. Vols. 1-8. Academia Republicii Romine, Bucuresti. 1965.

FUNGAL GENETICS, Vol. 4 (2nd edition). J. R S. Fincham and P. R. Day. Blackwell Scientific Publications, Oxford. 1965. Pp. 326. 55s.

GENETIK DER PILZE. Karl Esser und Rudolf Kuenen. Springer-Verlag, Berlin-West. 1965. Pp. 497. DM. 68.

HEREDITY AND THE NATURE OF MAN. Theodosius Dobzhansky. George Allen and Unwin Ltd., London, W.C.1. 1965. Pp. 179. 25s.

SIZE AND CYCLE. John T. Bonner. Oxford University Press, London, W.1. 1966. Pp. 219. 60s. 